\title{
SOEP $=$
}

SOEPpapers

SOEPpapers
on Multidisciplinary Panel Data Research

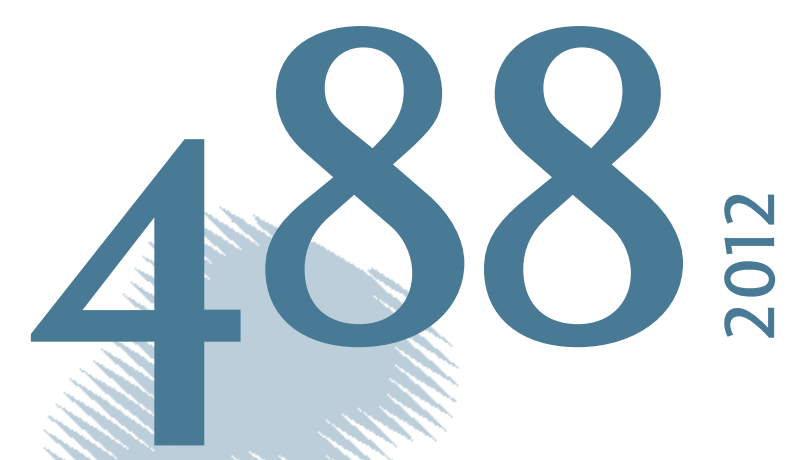

The effect of unemployment on the mental health of spouses - Evidence from plant closures in Germany 


\section{SOEPpapers on Multidisciplinary Panel Data Research}

at DIW Berlin

This series presents research findings based either directly on data from the German SocioEconomic Panel Study (SOEP) or using SOEP data as part of an internationally comparable data set (e.g. CNEF, ECHP, LIS, LWS, CHER/PACO). SOEP is a truly multidisciplinary household panel study covering a wide range of social and behavioral sciences: economics, sociology, psychology, survey methodology, econometrics and applied statistics, educational science, political science, public health, behavioral genetics, demography, geography, and sport science.

The decision to publish a submission in SOEPpapers is made by a board of editors chosen by the DIW Berlin to represent the wide range of disciplines covered by SOEP. There is no external referee process and papers are either accepted or rejected without revision. Papers appear in this series as works in progress and may also appear elsewhere. They often represent preliminary studies and are circulated to encourage discussion. Citation of such a paper should account for its provisional character. A revised version may be requested from the author directly.

Any opinions expressed in this series are those of the author(s) and not those of DIW Berlin. Research disseminated by DIW Berlin may include views on public policy issues, but the institute itself takes no institutional policy positions.

The SOEPpapers are available at

http://www.diw.de/soeppapers

\section{Editors:}

Jürgen Schupp (Sociology, Vice Dean DIW Graduate Center)

Gert G. Wagner (Social Sciences)

Conchita D'Ambrosio (Public Economics)

Denis Gerstorf (Psychology, DIW Research Professor)

Elke Holst (Gender Studies)

Frauke Kreuter (Survey Methodology, DIW Research Professor)

Martin Kroh (Political Science and Survey Methodology)

Frieder R. Lang (Psychology, DIW Research Professor)

Henning Lohmann (Sociology, DIW Research Professor)

Jörg-Peter Schräpler (Survey Methodology, DIW Research Professor)

Thomas Siedler (Empirical Economics)

C. Katharina Spieß (Empirical Economics and Educational Science)

ISSN: 1864-6689 (online)

German Socio-Economic Panel Study (SOEP)

DIW Berlin

Mohrenstrasse 58

10117 Berlin, Germany

Contact: Uta Rahmann | soeppapers@diw.de 


\title{
The effect of unemployment on the mental health of spouses - Evidence from plant closures in Germany
}

\author{
Jan Marcus ${ }^{1}$ (DIW Berlin)
}

\begin{abstract}
Studies on health effects of unemployment usually neglect spillover effects on spouses. This study specifically investigates the effect of an individual's unemployment on the mental health of their spouse. In order to allow for causal interpretation of the estimates, it focuses on an exogenous entry into unemployment (i.e. plant closure), and combines difference-in-difference and matching based on entropy balancing to provide robustness against observable and time-invariant unobservable heterogeneity. Using German SocioEconomic Panel Study data the paper reveals that unemployment decreases the mental health of spouses almost as much as for the directly affected individuals. The findings highlight that previous studies underestimate the public health costs of unemployment as they do not account for the potential consequences for spouses.
\end{abstract}

JEL: I12, J65

Keywords: unemployment, mental health, plant closure, entropy balancing, matching, job loss

\footnotetext{
${ }^{1}$ Jan Marcus, Mohrenstraße 58, DIW Berlin, 10117 Berlin, Germany; jmarcus@diw.de.
} 


\section{Introduction}

Apart from income, employment has many non-financial benefits, such as structured time, social status and identity, social contact, collective purpose, as well as activity (Jahoda 1979). Unemployment results in the loss of the pecuniary and non-pecuniary work benefits, and these losses also impact other household members. Spouses of newly unemployed individuals have to cope with reduced household income, a presumably more depressed partner, the partner's unfamiliar presence at home as well as a reduced social status. For spouses, too, these negative consequences of unemployment might result in depressive symptoms and other mental health issues.

Yet, while there is a whole branch of literature on the health implications of job loss and unemployment for those individuals directly affected (see e.g. Browning et al. 2006; Brand et al. 2008; Eliason \& Storrie 2009; Kuhn et al. 2009; Salm 2009; Sullivan \& Wachter 2009; Deb et al. 2011; Schmitz 2011; Browning \& Heinesen 2012; Marcus 2012), few studies address the impact on their spouses. Not considering the potential negative externalities on spouses might result in underestimating the public health costs of job loss (e.g. Kuhn et al. 2009). This study contributes to our understanding of spillover effects of unemployment on other household members by estimating the effect of unemployment on the spouse's mental health. In order to give the estimates a causal interpretation, this study applies a combination of matching and difference-in-difference that is robust against selection on observables and selection on unobservables with time-invariant effects. The matching part of the estimator constitutes one of the first applications of entropy balancing (Hainmueller 2012), which balances the conditioning variables more effectively than common propensity score methods. Furthermore, this study considers only unemployment resulting from plant closures. Other causes of unemployment might result from mental health issues and, hence, might be endogenous.

Using German Socio-Economic Panel Study (SOEP) data from 2002 through 2010, this paper finds that the unemployment of one spouse ${ }^{2}$ similarly affects the mental health of both spouses. About one year after plant closure, unemployment decreased mental health by $27 \%$ of a standard deviation for unemployed individuals themselves and by 19 $\%$ of a standard deviation for their spouses. In general, the decreases in mental health are larger when the male spouse enters unemployment. The results are robust over various matching specifications. Furthermore, this paper shows that changes in mental health do not differ between treated and matched controls before the plant closure, adding

\footnotetext{
${ }^{2}$ The terms "partner" and "spouse" are used interchangeably in this paper.
} 
additional credibility to the identification assumption.

The structure of this paper is as follows. The next section discusses related literature in greater detail, section 3 illustrates the estimation strategy, section 4 introduces the data, describes the construction of treatment and control group, and provides descriptive statistics. The main results are presented in section 5, while section 6 performs sensitivity analyses. Section 7 concludes.

\section{Related Literature}

The literature on the consequences of unemployment is closely related to the literature on the consequences of job loss - especially when the focus is on the identification of causal effects. In the following, I discuss these two branches of literature together, bearing in mind that not all individuals who lose their jobs are unemployed afterwards and not every individual in the state of unemployment experienced the event of an involuntary job loss.

Previous studies provide some evidence for spillover effects of job loss and unemployment on other household members. For instance, Winkelmann \& Winkelmann (1995) report decreases in subjective well-being following the partners' unemployment. Stephens (2002), using U.S. Panel Study of Income Dynamics (PSID) data, provides evidence for the "added worker effect", that women increase their labor supply due to their husbands' job losses. Again with PSID data, Charles \& Stephens (2004) show that job loss increases the probability of divorce. Other studies indicate that children are also affected by their parents' loss of employment. For instance, using SOEP data, Siedler (2011) finds that experiencing parental unemployment increases the probability of children to support extreme right-wing parties. With data from the PSID, Lindo (2011) provides evidence for a reduction in children's birth weight following a father's experience of plant closing. This already indicates that the public health costs of job loss are underestimated if spillover effects on other household members are not taken into account. Taken together, the findings on spillover effects on other household members lead to the expectation of negative consequences of unemployment for the spouse's mental health.

Few studies explicitly analyze the causal relationship between unemployment and the partner's mental health. Most of these studies focus on single plants or small geographic areas (e.g. Liem \& Liem 1988; Penkower et al. 1988; Dew et al. 1992). ${ }^{3}$ To my knowledge only two studies use nationally representative data in this context (Clark 2003; Siegel

\footnotetext{
${ }^{3}$ Dew et al. (1992) provide an overview over earlier qualitative studies on this topic.
} 
et al. 2003). However, both studies do not take into account the endogeneity of the treatment. Drawing on data from the British Household Panel Study, Clark (2003) finds partner's unemployment to reduce mental health, but less so if the respondent is already unemployed. Yet, this study does not differentiate between the reasons for unemployment. With data from the U.S. Health and Retirement Study (HRS) Siegel et al. (2003) do not find a significant effect of husbands' job loss on wives' mental health in general. However, this study also considers individuals who lost their job due to layoffs, which might result from mental health issues. Furthermore, due to the sampling design of the HRS, this study only analyzes individuals over the age of 50. In contrast, the present study looks at the entire range of working-age individuals and includes in the treatment group only individuals who lost their job due to plant closure.

\section{Estimation strategy}

In order to estimate the effect of unemployment on the mental health of couples, this paper combines matching and difference-in-difference (DiD), which is regarded to be superior to pure cross-sectional matching estimators (Heckman et al. 1997). This estimator brings together the literature on selection on observables with the literature on selection on unobservables. The idea of the estimator is rather simple. In the matching part of the estimator, I take couples who are affected by unemployment and similar couples who do not experience unemployment. In the DiD part, I compare changes in mental health of these two groups. The DiD part eliminates time-invariant mental health differences between couples in the treatment and control group that result from unobserved variables (like personality traits and differences in the reporting behavior). In all analyses I focus on the average treatment effect on the treated (ATT), i.e. the unemployment induced change in mental health of those couples who are actually affected by unemployment as a result of plant closures.

The challenge is how to make treated couples (couples, where one spouse is affected by unemployment resulting from plant closure) and control couples (couples without job loss experiences in the period) similar. To increase similarity between the two groups, propensity score methods are often applied (Caliendo \& Kopeinig 2008), ${ }^{4}$ where the control group observations are reweighted either by weights that depend directly on propensity score values (as in propensity score weighting) or by weights that depend

\footnotetext{
${ }^{4}$ The propensity score (Rosenbaum \& Rubin 1983) is the probability to receive the treatment conditional on the covariates.
} 
on propensity score distances to treatment observations (as, for example, in nearest neighbor or kernel matching). However, I do not take the detour via the propensity score, but instead implement a reweighting technique, entropy balancing (Hainmueller 2011, 2012), that focuses directly on the balancing of conditioning variables.

Entropy balancing reweights the control group observations in such a way that the control group satisfies pre-specified balancing requirements (here: same mean and variance of conditioning variables as in the treatment group). Among the possible sets of weights that fulfill these balancing requirements, entropy balancing choses the set of weights that deviates as little as possible from uniform weights (Hainmueller 2012). ${ }^{5}$ Entropy balancing spares the need to check for covariate balance since balance according to the pre-specified balancing requirements is fulfilled by construction. This makes the burdensome procedure of propensity score methods unnecessary, where "researchers 'manually' iterate between propensity score modeling, matching, and balance checking until they attain a satisfactory balancing solution" (Hainmueller 2012: 25). Entropy balancing is more effective as it improves the balance reached by common propensity score methods for all covariates. Furthermore, while propensity score methods often decrease balance on some covariates, entropy balancing improves balance for all conditioning variables. In contrast to propensity score methods, entropy balancing is fully non-parametric.

I perform entropy balancing separately for couples where the husband/wife enters unemployment. ${ }^{6}$ This is like exact matching on the gender of the directly affected spouse. Section 5 shows the results for all couples pooled and separately according to whether husband or wife enters unemployment. I require the control group to have the same mean and the same variance as the treatment group for all conditioning variables after entropy balancing. In applications of propensity score methods usually only the balance of the first moments is checked.

Obtaining the weights from entropy balancing constitutes the first step in implementing the estimation strategy. ${ }^{7}$ This is the matching/reweighting step. The second step is the regression step, where the change in mental health is regressed on the treatment indicator with the sampling weights obtained in the first step. In the regression step, I additionally control for all conditioning variables used in the matching step. This does not alter the treatment effect as after weighting the treatment is mean-independent of

\footnotetext{
${ }^{5}$ To compare deviations from uniform weights, entropy weighting uses the entropy divergence (Kullback 1959) as distance measure. Hence the name entropy balancing.

${ }^{6}$ For convenience, I refer to the male and female in a couple as husband and wife - independent of marital status.

${ }^{7}$ Entropy balancing is implemented using the program "ebalance" (Hainmueller 2011) in Stata 11.2.
} 
all conditioning variables. However, the regression-adjustment decreases the standard errors of the treatment effect estimates because it reduces unexplained variance in the outcome. This is similar to including control variables in randomized experiments.

Hence, the ATT of interest can be obtained from

$$
\widehat{\beta}=\left(\mathbf{X}^{\prime} \mathbf{W} \mathbf{X}\right)^{-1} \mathbf{X}^{\prime} \Delta y
$$

where $\Delta y$ is the vector of mental health changes and $\mathbf{W}$ a diagonal matrix with 1 in the diagonal cells for couples of the treatment group and entropy balancing weights in the diagonal cells for control group couples. $\mathbf{X}$ is a $n$-by- $(k+2)$ matrix, in which the first column consists of a vector of 1 s and the second column of the values of the treatment group indicator, $D$, for each couple. Additionally, $\mathbf{X}$ contains one column for each of the $k$ conditioning variables. The estimator is similar to the regression-adjusted semiparametric difference-in-difference matching strategy proposed by Heckman et al. (1997). It differs only with respect to the construction of the weights, which are computed by propensity score methods in Heckman et al. (1997).

In order to give the estimates a causal interpretation, the estimator has to assume that no unobserved variables exist that simultaneously influence changes in mental health and the probability of entering unemployment due to plant closure, i.e. in the absence of treatment (unemployment due to plant closure) the mental health of treated couples and matched control couples follows the same trend:

$$
E\left[Y_{0}^{a}-Y_{0}^{b} \mid E B(X), D=1\right]=E\left[Y_{0}^{a}-Y_{0}^{b} \mid E B(X), D=0\right]
$$

where $\Delta Y_{0}=Y_{0}^{a}-Y_{0}^{b}$ refers to the change in mental health from before $(b)$ to after (a) the treatment in the absence of treatment and $E B(X)$ refers to the weights from entropy balancing.

Besides this unconfoundedness assumption, a further requirement of matching estimators is the overlap condition $(P(D=1 \mid X)<1)$. It ensures that for any given $X$, there are not just treated observations but also control observations. It is not clear how to impose common support conditions for entropy balancing. Most studies relying on propensity score methods exclude treated observations whose propensity score exceeds the maximum of the propensity score in the control group in order to implement the common support for the ATT (Caliendo \& Kopeinig 2008). However, this common support condition is not binding in the present analysis since members of the control group have the highest propensity score values. 


\section{Data}

This paper makes use of data from the German Socio-Economic Panel (SOEP, v27) from 2002 through 2010. The SOEP is among the largest and longest running household panel surveys in the world. Annually about 20,000 individuals participate in the SOEP. It consists of several subsamples and is designed to be representative of the entire population in Germany (Wagner et al. 2007). The SOEP hosts several features that make it particularly attractive for the present analysis. Firstly, the longitudinal nature of the data ensures that I can observe the mental health scores before and after the treatment. Secondly, its large sample size facilitates analysis based on relatively rare events like plant closures. Thirdly, the SOEP contains not only information on one household member but also data on cohabiting spouses. These data are directly provided by the spouses themselves. Fourthly, after household dissolutions the SOEP follows all household members and not just the household head. This is of particular importance for the present analysis as unemployment increases the probability of divorce (Charles \& Stephens 2004) and, hence, household dissolution. Only considering couples that still live together after the treatment would result in a rather selective panel (though divorce related panel attrition might still occur in the SOEP; see below). Fifthly, the SOEP provides a wide range of information at the individual and the household level, including details about earnings, employment and living conditions. This enables me to include almost all conditioning variables used in related studies.

\subsection{Outcome}

Starting in 2002 the SOEP adopted a special health module that ever since is included every two years. The construction of the outcome variables reverts to this special health module and, more specifically, to the SOEP version of the SF-12 questionnaire therein. The SF-12 is a well established instrument to measure the overall health status in surveys (Andersen et al. 2007). It contains 12 health-related questions that encompass two dimensions of physical and mental health. All items reflect the current health status of the respondents, as they refer to the four weeks immediately prior to the interview (e.g. "How often did you feel run-down and melancholy in the last for weeks?"). Appendix A.1 provides an overview over the items of the SF-12 questionnaire and the answer categories.

Answers to items from this questionnaire form the basis of the outcome variable: a summary measure of mental health (Mental Component Summary Scale, MCS) that is a 
weighted combination of the 12 items and provided by the SOEP Group. It is computed by means of explorative factor analysis and transformed to have mean 50 and standard deviation 10 in the 2004 SOEP sample (Andersen et al. 2007). Higher values indicate a better mental health status. MCS is used widely in the epidemiologic literature and is found to be a reliable and valid indicator of mental illnesses (e.g. Salyers et al. 2000). A broad literature in economics uses this summary measure of mental health as well (e.g. Lechner 2009; Reichert \& Tauchmann 2011; Schmitz 2011).

\subsection{Treatment and Control Group}

Treatment and control group consist of couples who live together in the same household before the treatment - irrespective of their marital status. Figure 1 provides an overview of the construction of treatment and control group, which the following paragraph describes in more detail.

Figure 1: Construction of treatment and control group

\begin{tabular}{|l|}
\hline \multicolumn{1}{|c|}{ Before treatment } \\
Spouse 1 \\
Treatment and control group (same standard) \\
$-\quad$ Works full-time/part-time \\
$-\quad$ Employed in private sector \\
$-\quad$ Age: $18-62$ \\
Spouse 2 \\
Treatment and control group (same standard) \\
$-\quad$ Cohabiting \\
\hline
\end{tabular}

\begin{tabular}{|l|}
\hline \multicolumn{1}{|c|}{ After treatment } \\
Spouse 1 \\
Treatment group \\
$-\quad$ Unemployed due to plant closure \\
Control group \\
$-\quad$ No employer change \\
Spouse 2 \\
Treatment and control group (same standard) \\
$-\quad$ Same spouse \\
$-\quad$ No job loss due to plant closure \\
\hline
\end{tabular}

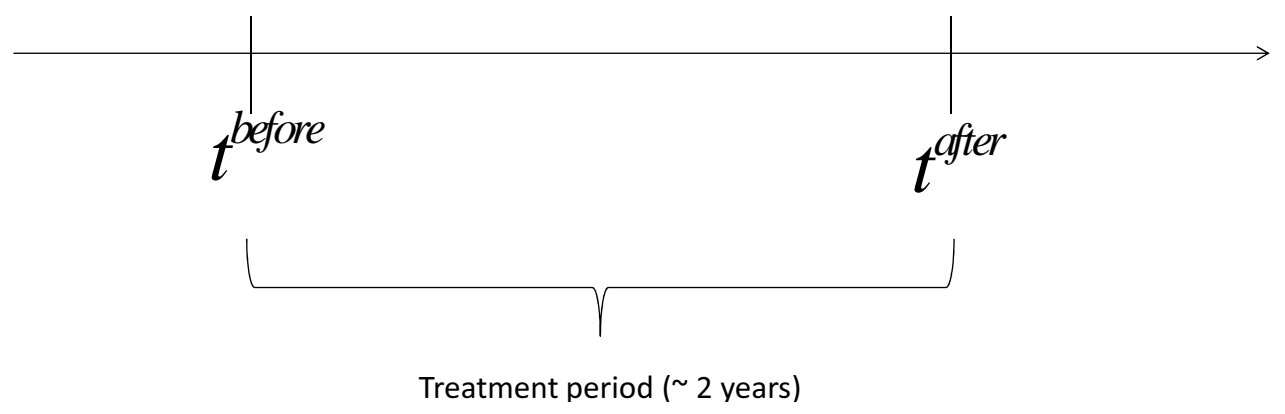

Note: The figure presents an overview of the construction of treatment and control group. The boxes show the requirements that couples have to meet to qualify for treatment and control group, respectively. "Spouse 1" refers to the directly affected individual and "spouse 2" to the partner of "spouse 1". 
I only include couples where both spouses participate in the survey before $\left(t^{b}\right)$ and after $\left(t^{a}\right)$ the treatment, and provide valid mental health information in both years. I do not consider same-sex couples as there are none in the treatment group.

The treatment group comprises couples in which one spouse (the "directly affected spouse") enters unemployment due to plant closure between two survey waves with the SF-12 questionnaire. I construct the treatment indicator by combining information from the question on whether the respondent is officially registered as unemployed with information on the reason why the individual left the last job. I only consider plant closures since other reasons of unemployment might be endogenous, e.g. someone might be dismissed because of shrinking work productivity due to marital problems (and marital problems might decrease mental health). Before the plant closure the directly affected individual has to be employed either full-time or part-time in the private sector and has to be between the ages of 18 and 62 . I include couples in the treatment group irrespective of age and employment status of the indirectly affected spouse (the partner of the directly affected individual). However, I do not consider couples in which the indirectly affected spouse experienced an involuntary job loss between $t^{b}$ and $t^{a}$ due to plant closure. That is done in order to prevent that own experiences deteriorate the mental health effect of the indirectly affected spouse. The plant closure experience of one spouse is likely to be correlated with a plant closure experience of the other spouse since spouses might work in the same plant. Excluding couples in which indirectly affected spouses experience plant closures themselves reduces the treatment group by $7 \%$.

The control group consists of a potentially directly affected individual (who is of the same sex as the directly affected individual in the treatment group) and a potentially indirectly affected individual. For the potentially indirectly affected spouse the same restrictions apply as in the treatment group construction, both before and after the treatment. Similarly to the treatment group, at the pre-treatment interview the potentially directly affected individual has to be employed either full-time or part-time in the private sector and has to be between the ages of 18 and 62 . However, couples qualify only for the control group, if the potentially directly affected spouse did not leave the previous employer during the treatment period (this excludes couples with any job loss experiences; see figure 1). This leaves more than 14,000 couples for the control group, compared to 109 couples in the treatment group: 70 couples in which the husband enters unemployment and 39 couples in which the wife enters unemployment.

The plant closure can take place at any time between two survey waves that include the mental health questions. Hence, there are four treatment periods: 2002-2004, 2004-2006, 
Table 1: Overview of the conditioning variables

Directly affected spouse

Demographic

Age

Female

Migrant

Non-German

in years

$0=$ male, $1=$ female

$1=$ individual or parents moved to Germany, 0 otherwise

$0=$ German, $1=$ foreign citizenship

Health

Physical health

Mental health

Often melancholic

Self-rated health

Labor market

Tenure

Labor earnings

Never unemployed

Years in full time

Company size

Perceived job security

Industry sector

based on SF12 questionnaire (see Andersen et al. 2007)

based on SF12 questionnaire

$0=$ never/almost never, $1=$ always/often/sometimes; part of SF12

3 categories (very good/good, satisfactory, poor/bad)

tenure with present employer (in years)

annual earnings in 1000 Euro

$0=$ ever unemployed, $1=$ never unemployed

previous full-time experience in years

4 categories ( $<20,20-200,200-2000, \geq 2000$ employees)

3 categories (big worries, some worries, no worries)

10 categories

\section{Educational}

Secondary schooling

University

Vocational training

4 categories (no degree/basic school, intermediate/other school, academic school track (Abitur), technical school)

$0=$ no university degree, $1=$ university degree

$0=$ no vocational training, $1=$ vocational training

\section{Indirectly affected spouse}

Age

Migrant

Non-German

Mental health

Labor earnings

Never unemployed

Working status

Secondary schooling

University

Vocational training

\section{Couple information}

Children

Regional unemployment

Residential district

Federal state

Survey year in years

$1=$ individual or parents moved to Germany, 0 otherwise

$0=$ German, $1=$ foreign citizenship

based on SF12 questionnaire

annual earnings in Euro

$0=$ ever unemployed, $1=$ never unemployed

3 categories (full time, part time, not employed)

4 categories (no degree/basic school, intermediate/other school, academic school track (Abitur), technical school)

$0=$ no university degree, $1=$ university degree

$0=$ no vocational training, $1=$ vocational training

$1=$ children under 18 in household, 0 otherwise

yearly information on the state level

4 cat. (<2000, 2000-20 000, 20 000-100 000, $\geq 100000$ inhabitants)

14 categories $^{8}$

4 categories $(2002,2004,2006,2008)$

${ }^{8}$ I group Bremen with Lower Saxony and Hamburg with Schleswig-Holstein due to few cases. 
2006-2008 and 2008-2010. I estimate treatment effects pooled over all four treatment periods. On average, I observe the treatment group 11 months after the plant closure. This time, however, varies between 0 and 23 months, with a rather uniform distribution. Hence, the estimates are to be interpreted as averages over these different unemployment durations; an interpretation inherent also to most applications of fixed effects panel estimators.

\subsection{Conditioning Variables}

The set of conditioning variables, i.e. $\mathbf{X}$ in equation (1), is selected following the screening of conditioning variables in other studies that analyze health effects of job loss and unemployment on the directly affected individual (Browning et al. 2006; Böckerman \& Ilmakunnas 2009; Eliason \& Storrie 2009; Salm 2009; Sullivan \& Wachter 2009; Schmitz 2011). These variables include demographic, labor market related, educational and health data. ${ }^{9}$ I can also condition on the job security perceived by the individuals, which can be seen as variable that captures unobserved factors related to the plant closure. Additionally the conditioning variables include characteristics of the indirectly affected spouse. Therefore, conditioning variables can be divided into variables reported by the directly affected individual, variables reported by the indirectly affected individual and variables on the couple (i.e. household) level. All 66 non-collinear conditioning variables originate from the pre-treatment interview. Table 1 provides an overview of the conditioning variables.

\subsection{Descriptive Statistics}

Table 2 presents summary statistics of selected conditioning variables separately for couples in the treatment and control group (before and after matching/reweighting). Table A.1 in the appendix provides the means of other conditioning variables.

The first two columns of table 2 display means of the conditioning variables for the treated and the control group couples, respectively. The last column displays differences in means between treatment and control group before matching and tests for the significance of these differences. Directly affected spouses differ in many respects significantly

\footnotetext{
${ }^{9}$ As the conditioning variables also include the pre-treatment values of the mental health score, the applied regression-adjusted matching DiD estimator resembles a regression-adjusted matching estimator, where the outcome is the post-treatment mental health score (Lechner 2010). I use the terminology matching DiD, in order to emphasize that the estimator provides also some robustness against selection on unobservables.
} 
from their control group counterparts. For instance, they are older (48.1 vs. 44.0 years), are less likely to be female, more often do not have the German citizenship and earn annually on average 10,000 Euro less. Individuals in the control group are almost three times more likely to have a university degree than individuals who experience unemployment due to plant closure (23.3\% vs. $8.3 \%$ ). However, before the treatment there are no significant differences with respect to tenure and mental health. The mental health score is only about 0.8 points (about $8 \%$ of a standard deviation) lower for the directly affected spouses in the treatment group and the difference is not statistically significant from zero.

Table 2: Summary statistics for selected variables before treatment

\begin{tabular}{|c|c|c|c|c|}
\hline \multirow[t]{2}{*}{ Variable } & \multirow[t]{2}{*}{ Treated } & \multicolumn{2}{|c|}{ Controls } & \multirow{2}{*}{$\begin{array}{c}\text { (unmatched) } \\
\text { Difference }\end{array}$} \\
\hline & & unmatched & matched & \\
\hline \multicolumn{5}{|c|}{ Directly affected spouse } \\
\hline Age & 48.1 & 44.0 & 48.1 & $-4.1^{* * *}$ \\
\hline Female $^{+}$ & 35.8 & 43.6 & 35.8 & $7.9^{*}$ \\
\hline Non-German $^{+}$ & 22.9 & 12.4 & 22.9 & $-10.5^{* * *}$ \\
\hline Mental health & 49.9 & 50.7 & 49.9 & 0.8 \\
\hline Tenure & 11.0 & 12.4 & 11.0 & 1.4 \\
\hline Never unemployed $^{+}$ & 62.4 & 70.6 & 62.4 & $8.2^{*}$ \\
\hline Labor earnings & 24.9 & 35.2 & 24.9 & $10.3^{* * *}$ \\
\hline Big job worries ${ }^{+}$ & 39.4 & 15.1 & 39.4 & $-24.3^{* * *}$ \\
\hline No job worries $^{+}$ & 22.0 & 39.0 & 22.0 & $16.9^{* * *}$ \\
\hline University $^{+}$ & 8.3 & 23.3 & 8.3 & $15.1^{* * *}$ \\
\hline \multicolumn{5}{|c|}{ Indirectly affected spouse } \\
\hline Mental health & 49.3 & 50.4 & 49.3 & 1.1 \\
\hline Works full-time ${ }^{+}$ & 49.5 & 52.2 & 49.5 & 2.7 \\
\hline Not working $^{+}$ & 31.2 & 22.7 & 31.2 & $-8.5^{* *}$ \\
\hline $\mathrm{N}$ & 109 & 14285 & 109 & \\
\hline
\end{tabular}

Note: The first three columns present means of selected variables before treatment for treated, controls and matched controls, respectively. ${ }^{+}$indicates that the mean represents a percentage share. The last column displays the difference in means between treatment and control group before matching; stars indicate significant $t$-test differences between these two groups: ${ }^{*} p<0.1 ;{ }^{* *} p<0.05 ;{ }^{* * *} p<0.01$.

Similarly, the indirectly affected spouses do not differ significantly from their control group counterparts with respect to mental health (49.3 vs 50.4), but with respect to age, German citizenship, education and earnings (see appendix table A.1). Of these indirectly affected spouses, $31.2 \%$ of them do not work, compared to $22.7 \%$ in the control group. 
The third column of table 2 reports means for the matched controls. After the reweighting based on entropy balancing the means in the control group equal the means in the treatment group. The applied entropy balancing scheme not only balances the means but also the variances of the conditioning variables.

Table A.1 in the appendix not only reports the means for other conditioning variables, but it also compares the matched control groups resulting a) from entropy balancing and b) the propensity score based kernel matching (Heckman et al. 1997). Kernel matching results rely on an Epanechnikov kernel and a bandwidth of 0.05, which improves the covariate balance particularly well compared to other propensity score based specifications. ${ }^{10}$ The table shows that also kernel matching works quite well. For all but one variable (technical college for the directly affected spouse) the standardized bias is below the value of 5, which is regarded to be low (Caliendo \& Kopeinig 2008). ${ }^{11}$ However, table A.1 also depicts that entropy balancing clearly outperforms kernel matching as it better improves covariate balance between treatment and control group. Kernel matching even increases the standardized bias for some variables (e.g. for living in a small city).

\section{Results}

Table 3 shows the results for the effect of unemployment on the mental health of couples. The table shows the findings pooled for all couples and separately according to the sex of the directly affected spouse. It starts with a simple specification and then gradually incorporates more sophisticated procedures. The first specification provides a simple comparison of the average mental health of treated and (all) controls after treatment. Since there might be fundamental differences between the treatment and control group (e.g. with respect to reporting behavior or the general mental health level), specification (2) uses the change in mental health as outcome. Hence, this specification resembles an ordinary difference-in-difference estimator without control variables. It might be that the mental health of treated couples follows a different trend than the mental health of other couples, i.e. even in the absence of treatment the mental health of the treated couples would change in a different way. The previous section shows that treated and control couples differ indeed in many respects. This makes it more likely that the treated

\footnotetext{
${ }^{10}$ For propensity score methods I also include the squared terms of all cardinal conditioning variables to improve balance on the second moments.

${ }^{11}$ The standardized bias is a measure of the matching quality, and defined as the difference between the means of treated and controls as a percentage share of the square root of the average of the variances in the two groups (see also table A.1).
} 
are on a different mental health track. Matching ensures that only comparable couples are compared. Specification (3) displays the results for the matching DiD estimator. Specification (4) is the preferred specification as, in addition to specification (3), it includes the covariates in the outcome equation as well. This leaves the estimates of the ATT unchanged, because by construction of the entropy balancing scheme, the treatment indicator is mean-independent of all conditioning variables. However, including the covariates in the outcome regression reduces the variance in the outcome and, hence, makes the estimates more precise.

Specification (1), the simple mean comparison, shows in the first cell that the mental health score of spouses who entered unemployment due to plant closure is on average about 2.68 units lower than the mental health score of control group individuals. This implies a difference of about $26.8 \%$ of a standard deviation since the mental health score is normed to have a standard deviation of 10 . For the spouses of the directly affected individuals, mental health is on average 2.59 points lower. The second and third panel show that the mental health is worse for both spouses irrespective of the sex of the directly affected spouse. However, the difference between treated and controls is more pronounced for couples where the husband became unemployed, and not significant for couples where the wife entered unemployment. In general, the differences are of similar magnitude for own mental health and the spouse's mental health, and not statistically significant from each other (as indicated by the p-values). This finding suggests that unemployment of one spouse similarly affects the mental health of both spouses.

The results for specification (2) are similar to the previous results, although the coefficient estimates decrease somewhat in magnitude (especially in the last panel). In the matching DiD estimator in specification (3) both standard errors and coefficient estimates slightly increase, t-statistics (not shown) marginally increase for most estimates. However, incorporating matching does not change the overall picture much.

The last column displays the results for the preferred specification, which includes regression-adjustment. In specification (4) unemployment decreases mental health for the directly affected individuals by 2.68 points on average, or about $26.8 \%$ of a standard deviation. This decrease is stronger when the husband enters unemployment (3.18 vs. 1.89 points). The impact of the spouse's unemployment is only slightly smaller for the indirectly affected spouse (1.94 points on average) and the difference in the effects is far from being statistically significant. Again, the effect is stronger if the husband enters unemployment (2.09 vs. 1.67 points). However, the effects of the wife's unemployment become significant in this last specification. These effects exhibit negative signs in all 
Table 3: The effect of unemployment on mental health - main results

\begin{tabular}{|c|c|c|c|c|}
\hline Outcome & $\begin{array}{c}\text { Mean } \\
\text { difference } \\
\quad(1)\end{array}$ & $\begin{array}{c}\mathrm{DiD} \\
(2)\end{array}$ & $\begin{array}{c}\text { Match } \\
(3)\end{array}$ & $\begin{array}{c}\text { Main } \\
\text { specification } \\
(4)\end{array}$ \\
\hline \multicolumn{5}{|l|}{ All couples } \\
\hline Own mental health & $\begin{array}{c}-2.68^{* *} \\
(1.04)\end{array}$ & $\begin{array}{c}-1.84 \\
(1.12)\end{array}$ & $\begin{array}{c}-2.72^{* *} \\
(1.16)\end{array}$ & $\begin{array}{c}-2.72^{* * *} \\
(0.74)\end{array}$ \\
\hline Partner's mental health & $\begin{array}{c}-2.59^{* *} \\
(1.01)\end{array}$ & $\begin{array}{r}-1.47^{*} \\
(0.84)\end{array}$ & $\begin{array}{c}-1.94^{* *} \\
(0.88)\end{array}$ & $\begin{array}{c}-1.94^{* * *} \\
(0.68)\end{array}$ \\
\hline p-value of difference & 0.94 & 0.78 & 0.57 & 0.38 \\
\hline \multicolumn{5}{|c|}{ Husband's unemployment } \\
\hline Own mental health & $\begin{array}{c}-3.22^{* *} \\
(1.35)\end{array}$ & $\begin{array}{r}-2.70^{*} \\
(1.53)\end{array}$ & $\begin{array}{c}-3.18^{* *} \\
(1.56)\end{array}$ & $\begin{array}{c}-3.18^{* * *} \\
(0.89)\end{array}$ \\
\hline Partner's mental health & $\begin{array}{c}-2.66^{* *} \\
(1.34)\end{array}$ & $\begin{array}{r}-2.04^{*} \\
(1.04)\end{array}$ & $\begin{array}{r}-2.09^{*} \\
(1.09)\end{array}$ & $\begin{array}{c}-2.09^{* * *} \\
(0.78)\end{array}$ \\
\hline$p$-value of difference & 0.73 & 0.71 & 0.54 & 0.29 \\
\hline \multicolumn{5}{|c|}{ Wife's unemployment } \\
\hline Own mental health & $\begin{array}{c}-2.02 \\
(1.62)\end{array}$ & $\begin{array}{c}-0.28 \\
(1.49)\end{array}$ & $\begin{array}{c}-1.89 \\
(1.59)\end{array}$ & $\begin{array}{c}-1.89^{* * *} \\
(0.69)\end{array}$ \\
\hline Partner's mental health & $\begin{array}{r}-2.11 \\
(1.45)\end{array}$ & $\begin{array}{c}-0.46 \\
(1.40)\end{array}$ & $\begin{array}{c}-1.67 \\
(1.50)\end{array}$ & $\begin{array}{c}-1.67^{* *} \\
(0.78)\end{array}$ \\
\hline p-value of difference & 0.96 & 0.93 & 0.91 & 0.80 \\
\hline
\end{tabular}

Note: The table presents the effect of one spouse's entry into unemployment on the mental health of both spouses. Each cell displays the ATT from a separate regression and its robust standard error in parentheses. Additionally, the table provides $p$-values for the $t$-tests whether unemployment differently influences directly and indirectly affected spouses. The upper panel considers all couples, while the two lower panel display results separately according to the sex of the directly affected spouse. The results rely on 109 couples in the treatment group (including 70 couples where the husband enters unemployment) and more than 14,000 couples in the control group. ${ }^{*} p<0.1$; ${ }^{* *} p<0.05$; *** $p<0.01$. The first column refers to the mean difference in mental health after the treatment and "DiD" to the simple difference-in-difference estimator without matching and "Match" to the DiD results after entropy balancing. The last column presents results for the matching DiD estimator that includes the covariates in the outcome equation. 
specifications but were not estimated precisely enough before. The results also suggest that the mental health decrease is slightly stronger for wives whose husbands enter unemployment than for wives who enter unemployment themselves. However, one can not interfere that women are more affected by the spouse's unemployment than by their own unemployment, as this might be two rather different groups of women (working wives vs. wives of working men). Similarly, one cannot say for sure that men are more affected by their unemployment than by their spouse's unemployment. In general, the coefficient estimates of the preferred specification closely resemble the results of specification (1), the simple mean comparison. This implies that selection into treatment is not strong with respect to mental health, which might provide additional credibility for studies that evaluate the impact of plant closures but do not observe the pre-treatment outcome.

It would be interesting to investigate whether the effect of unemployment differs between subgroups. However, due to the rather small number of couples in the treatment group - especially when only considering couples in which the wife enters unemployment - I refrain from more detailed inspections of potential mechanisms and treatment effect heterogeneity. ${ }^{12}$

\section{Sensitivity Analyses}

This section performs sensitivity analyses. It applies different matching procedures (propensity score weighting, kernel matching), analyzes the sensitivity of the results to a redefinition of the treatment and runs a placebo regression to check the plausibility of the identifying assumption. Table 4 presents the results for the various sensitivity analyses.

For the first two robustness checks I rely on propensity score methods instead of entropy balancing. Propensity score weighting (PSW) and kernel matching differ from entropy balancing with respect to the weighting matrix $W$ in equation (1). Propensity score weighting assigns to each control observation a weight that equals $1 /(1-P(X))$, where $P(X)$ is the propensity score. Kernel matching matches to each treatment observation control observations that are close in terms of the estimated propensity score. However, it does not assign equal weights to all the matched neighbors but instead as-

\footnotetext{
${ }^{12}$ Tentative analyses indicate that effects tend to be larger when the directly affected individual provided a higher share of household income before the plant closure and that larger decreases in one spouse's mental health are accompanied by larger decreases for the other spouse.
} 
Table 4: The effect of unemployment on mental health - sensitivity analyses

\begin{tabular}{|c|c|c|c|c|c|}
\hline Outcome & $\begin{array}{c}\text { Main } \\
\text { specification } \\
(4)\end{array}$ & $\begin{array}{c}\text { PS- } \\
\text { weighting } \\
(5)\end{array}$ & $\begin{array}{c}\text { PS- } \\
\text { matching } \\
(6)\end{array}$ & $\begin{array}{l}\text { All plant } \\
\text { closures } \\
(7)\end{array}$ & $\begin{array}{c}\text { Placebo } \\
\text { regress. } \\
(8)\end{array}$ \\
\hline \multicolumn{6}{|l|}{ All couples } \\
\hline Own mental health & $\begin{array}{c}-2.72^{* * *} \\
(0.74)\end{array}$ & $\begin{array}{c}-2.66^{* * *} \\
(0.72)\end{array}$ & $\begin{array}{c}-2.49^{* * *} \\
(0.72)\end{array}$ & $\begin{array}{r}-0.77 \\
(0.50)\end{array}$ & $\begin{array}{c}-0.23 \\
(0.64)\end{array}$ \\
\hline Partner's mental health & $\begin{array}{c}-1.94^{* * *} \\
(0.68)\end{array}$ & $\begin{array}{c}-1.99^{* * *} \\
(0.65)\end{array}$ & $\begin{array}{c}-1.82^{* * *} \\
(0.64)\end{array}$ & $\begin{array}{c}-1.27^{* * *} \\
(0.48)\end{array}$ & $\begin{array}{c}0.32 \\
(0.67)\end{array}$ \\
\hline p-value of difference & 0.38 & 0.43 & 0.43 & 0.40 & 0.48 \\
\hline $\mathrm{N}_{\text {Treated }}$ & 109 & 109 & 109 & 288 & 62 \\
\hline \multicolumn{6}{|c|}{ Husband's unemployment } \\
\hline Own mental health & $\begin{array}{c}-3.18^{* * *} \\
(0.89)\end{array}$ & $\begin{array}{c}-3.09^{* * *} \\
(0.85)\end{array}$ & $\begin{array}{c}-3.44^{* * *} \\
(0.94)\end{array}$ & $\begin{array}{c}-0.60 \\
(0.61)\end{array}$ & $\begin{array}{c}-0.89 \\
(0.59)\end{array}$ \\
\hline Partner's mental health & $\begin{array}{c}-2.09^{* * *} \\
(0.78)\end{array}$ & $\begin{array}{c}-2.22^{* * *} \\
(0.75)\end{array}$ & $\begin{array}{c}-1.76^{* *} \\
(0.81)\end{array}$ & $\begin{array}{r}-1.08^{*} \\
(0.59)\end{array}$ & $\begin{array}{c}0.02 \\
(0.57)\end{array}$ \\
\hline p-value of difference & 0.29 & 0.37 & 0.11 & 0.53 & 0.15 \\
\hline $\mathrm{N}_{\text {Treated }}$ & 70 & 70 & 70 & 194 & 33 \\
\hline \multicolumn{6}{|l|}{ Wife's unemployment } \\
\hline Own mental health & $\begin{array}{c}-1.89^{* * *} \\
(0.69)\end{array}$ & $\begin{array}{c}-1.73^{* * *} \\
(0.63)\end{array}$ & $\begin{array}{c}-1.70^{* * *} \\
(0.62)\end{array}$ & $\begin{array}{c}-1.10 \\
(0.68)\end{array}$ & $\begin{array}{c}0.53 \\
(0.75)\end{array}$ \\
\hline Partner's mental health & $\begin{array}{c}-1.67^{* *} \\
(0.78)\end{array}$ & $\begin{array}{c}-1.45^{* *} \\
(0.68)\end{array}$ & $\begin{array}{r}-1.13^{*} \\
(0.67)\end{array}$ & $\begin{array}{c}-1.68^{* * *} \\
(0.65)\end{array}$ & $\begin{array}{c}0.67 \\
(0.83)\end{array}$ \\
\hline$p$-value of difference & 0.80 & 0.73 & 0.51 & 0.45 & 0.90 \\
\hline $\mathrm{N}_{\text {Treated }}$ & 39 & 39 & 39 & 94 & 29 \\
\hline
\end{tabular}

Note: The table presents the effect of one spouse's entry into unemployment on the mental health of both spouses. Each cell displays the ATT from a separate regression and its robust standard error in parentheses. Additionally, the table provides the number of treated couples $\left(N_{\text {Treated }}\right)$ and $p$-values for the $t$-tests whether unemployment differently influences directly and indirectly affected spouses. The upper panel considers all couples, while the two lower panel display results separately according to the sex of the directly affected spouse. Specification (4) is the main estimation specification as in table 3, specifications (5) and (6) display the results for propensity score weighting and propensity score (kernel) matching, respectively. In specification (7) the treatment group comprises all couples that experienced a plant closure and specification (8) performs a placebo regression that pretends that the treatment takes place two years earlier. ${ }^{*} p<0.1 ;{ }^{* *} p<0.05 ;{ }^{* * *} p<0.01$. 
signs weights according to distances in the propensity score. ${ }^{13}$ Specifications (5) and (6) present the results for propensity score weighting and kernel matching, respectively. The effects are similar to the results in the main specification. However, the effects for wife's unemployment slightly decrease, while the effects for husband's unemployment on husband's and wife's mental health get more similar for propensity score weighting and more different for kernel matching. Also these specifications do not reject the nullhypothesis that unemployment influences directly and indirectly affected spouses in the same way, as indicated by the $p$-values.

As outlined in section 2, research on the consequences of unemployment is closely intertwined with research on the consequences of job loss. In order to make the results comparable to other studies that solely analyze job losses (e.g. Browning et al. 2006; Brand et al. 2008; Kuhn et al. 2009; Salm 2009), the treatment group in specification (7) comprises all couples that experienced a plant closure (irrespective of unemployment experiences). ${ }^{14}$ The results in table 4 indicate that plant closures per se do not have such negative impact on mental health. Rather, it is the unemployment experience that decreases mental health. Hence, failing to differentiate between job loss and unemployment might be a potential reason why existent studies do not find an effect of job loss on own mental health (e.g. Browning et al. 2006; Brand et al. 2008; Salm 2009). For both husbands and wives, own plant closure experiences do not significantly decrease own mental health. Contrary, plant closure experiences significantly decreases the spouse's mental health. This might suggest that job loss experiences have longer lasting consequences for spouses than for the directly affected individual. Also the effects on the spouses' mental health are smaller than in the main specification indicating that those with unemployment following a plant closure have larger drops in mental health. ${ }^{15}$ In specification (7), the mental health consequences are slightly larger for couples in which the wife experienced a plant closure.

To identify causal effects, all matching procedures assume that the conditioning variables include all variables simultaneously influencing changes in mental health and the probability of becoming unemployed due to plant closure. This assumption cannot be

${ }^{13}$ As in table A.1, for kernel matching I use the linear index of the propensity score and an Epanechnikov kernel with a bandwidth of 0.05 .

${ }^{14}$ Apart from this difference, the same rules for the selection of the treatment group apply as before (see figure 1 and section 4.2), in particular couples where both spouses experienced a plant closure are disregarded.

${ }^{15}$ Considering only couples that are included in specification (7) but not in specifications (1)-(6) indicates that only the effect of the wive's plant closure on the mental health of the spouse is significant (results are not shown, but are available upon request). 
directly tested. In order to add additional credibility to this assumption, I perform a placebo regression. For this purpose, I pretend that the treatment takes place two years earlier. Accordingly, for the first step I compute the weights based on conditioning variables obtained in the last year with health data before the placebo job loss. Specification (8) shows that the placebo treatment does not influence changes in mental health. All estimated effects are insignificant and close to zero. This specification adds plausibility to the assumption that the mental health of treated and matched controls follows a similar trend before the treatment.

Despite the robustness of the results to different matching procedures, the ATT estimates might be downward-biased for several reasons. First, there might be selective panel attrition. Couples experiencing a greater negative impact from unemployment (e.g. with respect to finances or identity) might be more likely to drop out of the sample. ${ }^{16}$ These couples might also be more likely to experience greater decreases in mental health. Related to this argument for selective panel attrition is the finding that job loss increases the risk to commit suicide (Eliason \& Storrie 2009), which is an extreme form of mental health problems. Similarly, also divorce increases the chances of panel attrition, ${ }^{17}$ and job loss increases the probability of divorce (Charles \& Stephens 2004). Second, the expectation of the plant closure might already decrease mental health. Hence, for treated couples the pre-treatment mental health score would be lower than their "normal" mental health score. Using German SOEP data, Reichert \& Tauchmann (2011) provide evidence that already the fear of becoming unemployed decreases mental health. Yet, specification (8) indicates that treated and matched controls do not differ with respect to their mental health trend before the treatment. One reason for this might be that the conditioning variables include also the perceived job security and that I, hence, compare only couples having similar risks of job loss. Third, the effects might be downward-biased since the analyses do not include couples in which both spouses experience a plant closing. Due to all these reasons, the estimated effects can be rather regarded as lower bound estimates.

\footnotetext{
${ }^{16}$ For instance, Dorsett (2010) finds unemployment to be related to panel attrition when comparing survey and register data.

${ }^{17}$ Although the SOEP following rules should mitigate divorce related panel attrition, see section 4 .
} 


\section{Conclusion}

This paper analyzes spillover effects of unemployment on other household members by estimating the causal effect of unemployment on spouse's mental health. Using data from the German Socio-Economic Panel Study (SOEP) from 2002 through 2010, this paper finds that unemployment of one spouse similarly affects the mental health of both spouses. About one year after the plant closure, unemployment decreases mental health by $27 \%$ of a standard deviation for the unemployed individuals themselves and by 19 $\%$ of a standard deviation for their spouses. In general, the decreases in mental health are larger when the husband enters unemployment. The findings are robust over various matching specifications.

In order to give the estimates a causal interpretation, this study focuses on an exogenous entry into unemployment (i.e. plant closure), and applies a combination of matching and difference-in-difference estimation that is robust against selection on observables and selection on unobservables with time-invariant effects. The matching part of the estimator constitutes one of the first applications of entropy balancing (Hainmueller 2012), which balances the conditioning variables more effectively than common propensity score methods. The estimation strategy assumes that no unobserved variables exist that simultaneously influence changes in mental health and the probability of entering unemployment due to plant closure. This paper provides an indirect test to show that this identifying assumption is not violated, as mental health does not follow a different trend for treated and matched controls before the plant closure.

The findings highlight that unemployment has severe consequences not just for the directly affected individuals, but also for their spouses. Hence, previous studies underestimate the public health costs of job loss as they do not consider the consequences for spouses. When comparing costs and benefits of labor market policies to prevent unemployment, policy-makers should take into account that employment has non-financial benefits not only for the employed individuals themselves but also for their spouses. 


\section{References}

Andersen, H. H., Mühlbacher, A., Nübling, M., Schupp, J., \& Wagner, G. G. (2007). Computation of standard values for physical and mental health scale scores using the SOEP version of SF-12v2. Schmollers Jahrbuch, 127(1), 171-182.

Böckerman, P. \& Ilmakunnas, P. (2009). Unemployment and self-assessed health: Evidence from panel data. Health Economics, 18(2), 161-179.

Brand, J. E., Levy, B. R., \& Gallo, W. T. (2008). Effects of layoffs and plant closings on depression among older workers. Research on Aging, 30(6), 701-721.

Browning, M., Dano, A. M., \& Heinesen, E. (2006). Job displacement and stress-related health outcomes. Health Economics, 15(10), 1061-1075.

Browning, M. \& Heinesen, E. (2012). Effect of job loss due to plant closure on mortality and hospitalization. Journal of Health Economics, 31(4), 599-616.

Caliendo, M. \& Kopeinig, S. (2008). Some practical guidance for the implementation of propensity score matching. Journal of Economic Surveys, 22(1), 31-72.

Charles, K. K. \& Stephens, M. (2004). Job displacement, disability, and divorce. Journal of Labor Economics, 22(2), 489-522.

Clark, A. E. (2003). Unemployment as a social norm: Psychological evidence from panel data. Journal of Labor Economics, 21(2), 323-351.

Deb, P., Gallo, W. T., Ayyagari, P., Fletcher, J. M., \& Sindelar, J. L. (2011). The effect of job loss on overweight and drinking. Journal of Health Economics, 30(2), 317-327.

Dew, M. A., Bromet, E. J., \& Penkower, L. (1992). Mental health effects of job loss in women. Psychological Medicine, 22(3), 751-764.

Dorsett, R. (2010). Adjusting for nonignorable sample attrition using survey substitutes identified by propensity score matching: An empirical investigation using labour market data. Journal of Official Statistics, 26(1), 105-125.

Eliason, M. \& Storrie, D. (2009). Does job loss shorten life? Journal of Human Resources, 44(2), 277-302.

Hainmueller, J. (2011). Ebalance: A Stata package for entropy balancing. MIT Political Science Department Research Paper, 24.

Hainmueller, J. (2012). Entropy balancing for causal effects: A multivariate reweighting method to produce balanced samples in observational studies. Political Analysis, 20, $25-46$. 
Heckman, J., Ichimura, H., \& Todd, P. E. (1997). Matching as an econometric evaluation estimator: Evidence from evaluating a job training programme. The Review of Economic Studies, 64(4), 605-654.

Jahoda, M. (1979). The impact of unemployment in the 1930s and the 1970s. Bulletin of the British Psychological Society.

Kuhn, A., Lalive, R., \& Zweimüller, J. (2009). The public health costs of job loss. Journal of Health Economics, 28(6), 1099-1115.

Kullback, S. (1959). Information theory and statistics. New York.

Lechner, M. (2009). Long-run labour market and health effects of individual sports activities. Journal of Health Economics, 28(4), 839-854.

Lechner, M. (2010). The estimation of causal effects by difference-in-difference methods. University of St. Gallen Department of Economics Working Paper Series, 28.

Liem, R. \& Liem, J. H. (1988). Psychological effects of unemployment on workers and their families. Journal of Social Issues, 44(4), 87-105.

Lindo, J. (2011). Parental job loss and infant health. Journal of Health Economics, 20(5), 869-879.

Marcus, J. (2012). Does job loss make you smoke and gain weight? SOEPpapers on Multidisciplinary Panel Data Research, 432.

Penkower, L., Bromet, E. J., \& Dew, M. A. (1988). Husbands' layoff and wives' mental health: A prospective analysis. Archives of General Psychiatry, 45(11), 994-1000.

Reichert, A. \& Tauchmann, H. (2011). The causal impact of fear of unemployment on psychological health. Ruhr Economic Papers, 266.

Rosenbaum, P. R. \& Rubin, D. B. (1983). The central role of the propensity score in observational studies for causal effects. Biometrika, 70(1), 41-55.

Salm, M. (2009). Does job loss cause ill health? Health Economics, 18(9), 1075-1089.

Salyers, M. P., Bosworth, H. B., Swanson, J. W., Lamb, J., \& Osher, F. C. (2000). Reliability and validity of the SF-12 health survey among people with severe mental illness. Medical Care, 38(11), 1141-1150.

Schmitz, H. (2011). Why are the unemployed in worse health? The causal effect of unemployment on health. Labour Economics, 18(1), 71-78.

Siedler, T. (2011). Parental unemployment and young people's extreme right-wing party affinity: Evidence from panel data. Journal of the Royal Statistical Society: Series A (Statistics in Society), 174(3), 737-758. 
Siegel, M. J., Bradley, E. H., Gallo, W. T., \& Kasl, S. V. (2003). Impact of husbands' involuntary job loss on wives' mental health, among older adults. The Journals of Gerontology. Series B, Psychological Sciences and Social Sciences, 58(1), S30-S37.

Stephens, M. (2002). Worker displacement and the added worker effect. Journal of Labor Economics, 20(3), 504-537.

Sullivan, D. G. \& Wachter, T. (2009). Job displacement and mortality: An analysis using administrative data. Quarterly Journal of Economics, 124(3), 1265-1306.

Wagner, G., Frick, J., \& Schupp, J. (2007). The German Socio-Economic Panel Study (SOEP) - Scope, evolution and enhancements. Schmollers Jahrbuch, 127(1), 139-169.

Winkelmann, L. \& Winkelmann, R. (1995). Happiness and unemployment: A panel data analysis for Germany. Konjunkturpolitik, 41(4), 293-307. 


\section{A Appendix}

Figure A.1: Overview of the SOEP version of the SF-12 questions

99. How would you describe your current health?

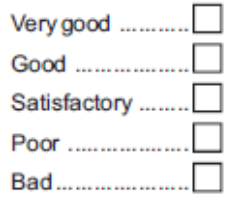

100. When you ascend stairs, i.e. go up several floors on foot

Does your state of health affect you greatly, slightly or not at all?

Greatly.

Slightly.

Not at all

101. And what about having to cope with other tiring everyday tasks,

i.e. when one has to lift something heavy or when one requires agility:

Does your state of health affect you greatly, slightly or not at all?

Greatly.

Slightly.

Not at all

102. Please think about the last four weeks. How often did it occur within this period of time, times

- that you felt rushed or pressed for time?

- that you felt run-down and melancholy?

- that you felt relaxed and well-balanced?

- that you used up a lot of energy?

- that you had strong physical pains?

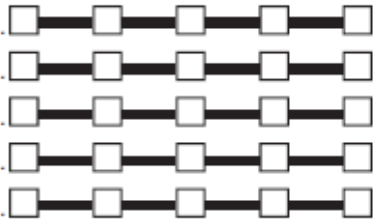

- that due to physical health problems

- you achieved less than you wanted to at work or in everyday tasks?

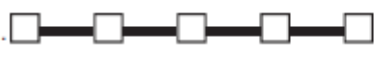

- you were limited in some form at work or in everyday tasks?

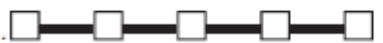

- that due to mental health or emotional problems

- you achieved less than you wanted to at work or in everyday tasks?

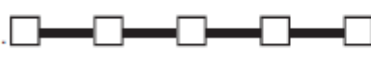

- you carried out your work or everyday tasks less theroughly than usual?

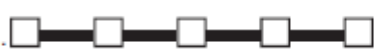

- that due to physical or mental health problems you were limited socially, i.e. in contact with friends, acquantances or relatives?

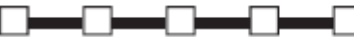


Table A.1: Descriptive statistics - means and standardized bias

\begin{tabular}{|c|c|c|c|c|c|c|c|}
\hline \multirow[b]{2}{*}{ Variable } & \multirow[t]{2}{*}{$\begin{array}{l}\text { Means } \\
\text { treated }\end{array}$} & \multicolumn{3}{|c|}{$\begin{array}{c}\text { Means } \\
\text { controls }\end{array}$} & \multicolumn{3}{|c|}{ Standard. Bias (\%) } \\
\hline & & raw & EB & kernel & raw & EB & kernel \\
\hline \multicolumn{8}{|l|}{ Directly affected spouse } \\
\hline Age & 48.1 & 44.0 & 48.1 & 48.2 & 45.4 & 0.0 & -1.4 \\
\hline Female $^{+}$ & 35.8 & 43.6 & 35.8 & 35.8 & -16.1 & 0.0 & -0.0 \\
\hline Migrant $^{+}$ & 23.9 & 15.3 & 23.9 & 22.9 & 21.7 & 0.0 & 2.1 \\
\hline Non-German $^{+}$ & 22.9 & 12.4 & 22.9 & 22.2 & 27.8 & 0.0 & 1.7 \\
\hline Physical health & 49.8 & 52.2 & 49.8 & 50.1 & -28.0 & 0.0 & -3.7 \\
\hline Mental health & 49.9 & 50.7 & 49.9 & 49.9 & -9.6 & 0.0 & -0.3 \\
\hline Often melancholic $^{+}$ & 51.4 & 46.2 & 51.4 & 50.1 & 10.4 & 0.0 & 2.5 \\
\hline Bad health $^{+}$ & 14.7 & 9.3 & 14.7 & 13.0 & 16.4 & 0.0 & 4.7 \\
\hline Medium health $^{+}$ & 34.9 & 32.5 & 34.9 & 35.5 & 5.0 & 0.0 & -1.4 \\
\hline Good health $^{+}$ & 50.5 & 58.1 & 50.5 & 51.4 & -15.4 & 0.0 & -1.9 \\
\hline Tenure & 11.0 & 12.4 & 11.0 & 10.9 & -14.6 & 0.0 & 1.1 \\
\hline Labor earnings & 24.9 & 35.2 & 24.9 & 25.2 & -46.3 & 0.0 & -1.9 \\
\hline Never unemployed ${ }^{+}$ & 62.4 & 70.6 & 62.4 & 62.8 & -17.4 & 0.0 & -0.8 \\
\hline Small company ${ }^{+}$ & 33.9 & 19.9 & 33.9 & 32.5 & 32.0 & 0.0 & 3.0 \\
\hline Medium-small company $^{+}$ & 45.9 & 30.5 & 45.9 & 46.7 & 31.9 & 0.0 & -1.7 \\
\hline Medium company $^{+}$ & 11.9 & 24.0 & 11.9 & 12.5 & -31.8 & 0.0 & -1.6 \\
\hline Large company $^{+}$ & 8.3 & 23.5 & 8.3 & 8.3 & -42.5 & 0.0 & -0.2 \\
\hline Big job worries ${ }^{+}$ & 39.4 & 15.1 & 39.4 & 39.5 & 56.6 & 0.0 & -0.1 \\
\hline Some job worries ${ }^{+}$ & 38.5 & 45.9 & 38.5 & 39.5 & -15.0 & 0.0 & -1.9 \\
\hline No job worries ${ }^{+}$ & 22.0 & 39.0 & 22.0 & 21.0 & -37.4 & 0.0 & 2.4 \\
\hline Years full-time & 21.2 & 18.0 & 21.2 & 21.2 & 29.3 & 0.0 & 0.2 \\
\hline Primary sector ${ }^{+}$ & 0.0 & 1.3 & 0.00 & 0.0 & -16.4 & 0.0 & 0.0 \\
\hline Manufacturing $^{+}$ & 39.4 & 30.0 & 39.4 & 39.3 & 19.9 & 0.0 & 0.3 \\
\hline Energy and water ${ }^{+}$ & 0.0 & 1.3 & 0.00 & 0.0 & -16.0 & 0.0 & 0.0 \\
\hline Construction $^{+}$ & 13.8 & 5.5 & 13.8 & 13.1 & 28.0 & 0.0 & 1.9 \\
\hline Wholesale and retail ${ }^{+}$ & 23.9 & 11.8 & 23.9 & 24.8 & 31.9 & 0.0 & -2.1 \\
\hline Hotel and restaurants ${ }^{+}$ & 0.9 & 1.4 & 0.9 & 1.0 & -4.4 & 0.0 & -1.2 \\
\hline Transport $^{+}$ & 1.8 & 5.3 & 1.8 & 1.8 & -18.5 & 0.0 & 0.3 \\
\hline Banking and insurance $^{+}$ & 2.8 & 5.1 & 2.8 & 2.4 & -12.3 & 0.0 & 2.3 \\
\hline Health services ${ }^{+}$ & 2.8 & 11.7 & 2.8 & 2.9 & -35.1 & 0.0 & -0.9 \\
\hline Other services ${ }^{+}$ & 11.0 & 23.3 & 11.0 & 11.7 & -33.0 & 0.0 & -2.3 \\
\hline Basic school $^{+}$ & 45.0 & 29.1 & 45.0 & 45.4 & 33.2 & 0.0 & -0.9 \\
\hline Intermediate school $^{+}$ & 45.0 & 44.9 & 45.0 & 42.8 & 0.1 & 0.0 & 4.3 \\
\hline Technical college $^{+}$ & 2.8 & 6.8 & 2.8 & 3.8 & -19.1 & 0.0 & -5.7 \\
\hline Highest secondary $^{+}$ & 7.3 & 19.2 & 7.3 & 8.0 & -35.4 & 0.0 & -2.4 \\
\hline University $^{+}$ & 8.3 & 23.3 & 8.3 & 9.5 & -42.2 & 0.0 & -4.2 \\
\hline Vocational training $^{+}$ & 78.9 & 76.8 & 78.9 & 78.1 & 4.9 & 0.0 & 2.0 \\
\hline
\end{tabular}


Table A.1: Descriptive statistics - means and standardized bias, continued

\begin{tabular}{|c|c|c|c|c|c|c|c|}
\hline \multirow[b]{2}{*}{ Variable } & \multirow[t]{2}{*}{$\begin{array}{l}\text { Means } \\
\text { treated }\end{array}$} & \multicolumn{3}{|c|}{$\begin{array}{c}\text { Means } \\
\text { controls }\end{array}$} & \multicolumn{3}{|c|}{ Standard. Bias (\%) } \\
\hline & & raw & $\mathrm{EB}$ & kernel & raw & $\mathrm{EB}$ & kernel \\
\hline \multicolumn{8}{|c|}{ Indirectly affected spouse } \\
\hline Age & 47.2 & 44.0 & 47.2 & 47.7 & 31.4 & 0.0 & -4.1 \\
\hline Migrant ${ }^{+}$ & 26.6 & 15.4 & 26.6 & 25.0 & 27.7 & 0.0 & 3.6 \\
\hline Non-German $^{+}$ & 22.9 & 12.4 & 22.9 & 21.9 & 27.7 & 0.0 & 2.4 \\
\hline Mental health & 49.3 & 50.4 & 49.3 & 49.4 & -11.7 & 0.0 & -1.0 \\
\hline Labor earnings & 21.0 & 24.6 & 21.0 & 20.8 & -14.4 & 0.0 & 0.6 \\
\hline Never unemployed ${ }^{+}$ & 56.9 & 65.1 & 56.9 & 57.6 & -17.0 & 0.0 & -1.5 \\
\hline Works full-time $^{+}$ & 49.5 & 52.2 & 49.5 & 48.3 & -5.4 & 0.0 & 2.6 \\
\hline Works part-time $^{+}$ & 19.3 & 25.1 & 19.3 & 20.6 & -14.1 & 0.0 & -3.2 \\
\hline Not working ${ }^{+}$ & 31.2 & 22.7 & 31.2 & 31.2 & 19.3 & 0.0 & 0.0 \\
\hline Basic school $^{+}$ & 36.7 & 28.1 & 36.7 & 37.9 & 18.5 & 0.0 & -2.5 \\
\hline Intermediate school $^{+}$ & 48.6 & 46.1 & 48.6 & 48.0 & 5.0 & 0.0 & 1.3 \\
\hline Technical college $^{+}$ & 6.4 & 6.4 & 6.4 & 5.5 & 0.1 & 0.0 & 3.8 \\
\hline Highest secondary $^{+}$ & 8.3 & 19.4 & 8.3 & 8.6 & -32.7 & 0.0 & -1.3 \\
\hline University $^{+}$ & 11.9 & 22.4 & 11.9 & 11.6 & -28.0 & 0.0 & 1.1 \\
\hline Vocational training ${ }^{+}$ & 74.3 & 75.4 & 74.3 & 73.2 & -2.4 & 0.0 & 2.6 \\
\hline \multicolumn{8}{|l|}{ Couple information } \\
\hline Children $^{+}$ & 37.6 & 49.8 & 37.6 & 36.9 & -24.7 & 0.0 & 1.4 \\
\hline Regional unemployment & 9.6 & 10.2 & 9.6 & 9.6 & -13.7 & 0.0 & -0.3 \\
\hline Village $^{+}$ & 11.0 & 9.1 & 11.0 & 10.6 & 6.5 & 0.0 & 1.4 \\
\hline Small town ${ }^{+}$ & 37.6 & 35.8 & 37.6 & 38.7 & 3.7 & 0.0 & -2.2 \\
\hline Small city ${ }^{+}$ & 27.5 & 28.1 & 27.5 & 26.5 & -1.3 & 0.0 & 2.4 \\
\hline Big city $^{+}$ & 23.9 & 27.0 & 23.9 & 24.3 & -7.2 & 0.0 & -1.0 \\
\hline Year $2002^{+}$ & 40.4 & 28.4 & 40.4 & 39.3 & 25.3 & 0.0 & 2.3 \\
\hline Year $2004^{+}$ & 23.9 & 25.6 & 23.9 & 24.3 & -4.1 & 0.0 & -1.0 \\
\hline Year $2006^{+}$ & 11.9 & 24.6 & 11.9 & 10.9 & -33.1 & 0.0 & 3.1 \\
\hline Year $2008^{+}$ & 23.9 & 21.4 & 23.9 & 25.5 & 5.9 & 0.0 & -3.9 \\
\hline $\mathrm{N}$ & 109 & 14285 & & & & & \\
\hline
\end{tabular}

Note: Summary statistics for treated couples, all control couples and matched control couples. The first two columns present the means of selected variables before treatment for treated and controls. Third and fourth column show the means for the reweighted control group according to entropy balancing (EB) and kernel matching, a propensity score method. The last three columns display a measure for the quality of the matching process. The standardized bias is defined for each conditioning variable $s$ as $S B_{s}=100 \cdot \frac{\overline{s_{1}}-\overline{s_{0}}}{\sqrt{\frac{1}{2}\left(\sigma_{s 1}^{2}+\sigma_{s 0}^{2}\right)}}$, where $\overline{s_{1}}$ and $\overline{s_{0}}$ are the means of treated and controls, respectively, and $\sigma_{s 1}^{2}$ and $\sigma_{s 0}^{2}$ the corresponding variances. ${ }^{+}$indicates that the mean represents a percentage share. 